Original Research Paper

\title{
Determining the Hazardous Medical Waste Generation Rates of Private Health Care Facilities-Case Study from Dhaka City of Bangladesh
}

\author{
Md. Yousuf Rumi and Rezaul Karim \\ Deptartment of Civil and Environmental Engineering, Islamic University of Technology, Gazipur, Bangladesh
}

\author{
Article history \\ Received: 08-10-2017 \\ Revised: $12-03-2018$ \\ Accepted: 24-04-2018 \\ Corresponding Author: \\ Md. Yousuf Rumi \\ Deptartment of Civil and \\ Environmental Engineering, \\ Islamic University of \\ Technology, Gazipur, \\ Bangladesh \\ Email: yousufrumi@iut-dhaka.edu
}

\begin{abstract}
Many developing countries are lagging behind the developed countries to properly manage their hazardous healthcare waste. These waste pose a significant epidemiological risks to the general people. To estimate the epidemiological risks and to establish parameters of any waste management plan, quantitative estimation of healthcare waste generation is essential. Most researches on quantitative estimation of healthcare wastes to date, have not addressed the differences in waste generation trends between the government and private healthcare sectors. This study was carried out to estimate the hazardous healthcare waste generation from private healthcare sector of Bangladesh; with a future aim do the same for government healthcare sector. A total of 50 privates healthcare facilities of different categories from Dhaka North City Corporation (DNCC) and Dhaka South City Corporation (DSCC) were selected for this study following a random sampling technique. Secondary data was obtained from PRISM Bangladesh (PRISM Bangladesh Foundation is a non-profit voluntary development organization established in 1989. In the context of environmental management, PRISM Bangladesh operates in different areas of Bangladesh with the assistance and support of UN organizations such as UNDP, UNICEF, UNDRO and UNCDF.) for these 50 healthcare facilities and personal visits to waste treatment sites were made. The estimated the hazardous healthcare waste generation rate for the private healthcare sector was found to be $0.17 \mathrm{~kg} \mathrm{bed}^{-1} \mathrm{day}^{-1}$ on per patient per day basis and an overall of $6796 \mathrm{~kg}$ daily. The estimated waste quantity and the proportion of hazardous healthcare waste to total healthcare waste was found to vary significantly due to different parameters related to the type and size of healthcare facility, seasonal variation etc. Based on the findings of this research, more accurate strategic planning of waste management systems for developing countries can be established by governments and municipal authorities to reduce the epidemiological risks.
\end{abstract}

Keywords: Developing Countries, Epidemiological Risks, Hazardous Waste Generation Rate, Private Healthcare Sector, Waste Management Plan

\section{Introduction}

Often in developing countries, proper waste management system does not exist. These developing countries such as Brazil, Argentina, India, Pakistan, Bangladesh, Nepal etc. have established small scale waste management systems. Aside from deep burial of hazardous wastes, autoclaving and incineration technologies are used in the aforementioned counties for hazardous medical waste treatment. The performance of incinerators are subpar in developing countries and sometimes they remain non-operational due to lack of funding and proper maintenance. Incinerators may emit a wide range of pollutants such as particulate matter, mercury, dioxin and furans (Shinee et al., 2008). JICA (2005) suggested that incineration as well as unproven technologies such as Plasma should not be considered as an option for the treatment of municipal solid waste for low calorific value and environmental pollution potential. For the treatment of infectious/hazardous 
biomedical waste in absence of an appropriate non-burn technology, some appropriate incineration technologies can be considered. Normally, medical institutions focus on the installation of waste disposal technologies such as incineration but remain unable to enforce the waste management practices within the facility. Internationally, there are some popular techniques which are used in different countries such as incineration, microwave disinfection, autoclave disinfection and chemical/mechanical disinfection. Akter (2000) reported the use of other cheap methods of medical waste disposal, e.g., burial, burning, dumping, removal of municipal bins and selling etc., especially in the developing countries.

Medical waste may contain highly toxic chemicals and can present a mechanism for transmission of diseases (Silva et al., 2005). The growth of the medical sector around the world over the last decade combined with an increase in the use of disposable cheap medical products has contributed to the large amount of medical waste being generated (Silva et al., 2005). Different researches including Muhlich et al. (2003) illustrate that only small proportion of overall medical waste considered as hazardous wast e, yet the main sources of hazardous/toxic waste are clinics and hospitals, whereas a small amount of hazardous waste also comes from industrial and domestic sources. As described by WHO (1994), almost 85\% hospital waste are non-hazardous, around $10 \%$ infectious and only $5 \%$ are hazardous but noninfectious. This range varies in the case of different countries. For example, in the United States, almost 15\% of hospital waste is considered as infectious waste. In the case of India, this range varies between $15-35 \%$, whereas in the case of Bangladesh, around 10-25\% of the hospital waste is considered as potentially hazardous or infectious. This variation depends on the overall amount of waste which is generated within the country (Akter, 2000).

Improper hospital waste management directly or indirectly affects the whole environmental system in the form of water and soil contamination. Due to lack of proper management and waste disposal system, there are many significant health problems especially in developing countries, such as skin allergies, eyes irritation, diarrhea, fever, cholera, typhoid influenza and allergy are the most common problems especially among workers, patients and communities (Ahmed, 1997). Although everyone who is exposed to hazardous waste is potentially at risk, it is the group of people who directly belong to medical profession, as well as waste workers, scavengers, patients and their visitors in the hospital who are highly at risk. Different researches illustrate that there are numerous diseases which can be transmitted among the group of people who are highly at risk but most significant diseases are Hepatitis B and C, as well as and Acquired Immunodeficiency Syndrome (AIDs) (Rasheed et al., 2005; Kumar et al., 2010).
Bangladesh is a developing country with a rapidly growing urban population, extensive health problems, low educational status and environmental pollution (Kabir et al., 2003). Dhaka, Chittagong, Gazipur and Khulana are the only cities where some form of healthcare waste management systems are practiced. In other cities, hospital waste is collected by sweepers and then transported to the city's open waste dumping sites. In Government hospitals, there are no special techniques for waste handling and due to lack of awareness, hospital staff normally treats all solid wastes carelessly. Municipal transport is used to collect and dispose of the hospital waste in any open dumping site alongside city garbage. Normally, hospital waste and domestic waste are mixed together on the roadside and then disposed of. Sometimes, to get rid of this waste, it is simply buried without complying with any rules and regulations (JICA, 2005). The bitter reality behind such actions is that although the necessary technologies and equipment are available to ensure proper hospital waste management within the country, the unawareness among staff and local people regarding effective disposal techniques and policies hinders their implementation. However, Bangladesh is at a crucial stage where there is an urgent need to create awareness about the hazardous impacts of waste on human health as well as the environment. Moreover, strict measures are needed to implement hospital waste management technologies.

In light of the epidemiological risks posed by untreated hospital wastes, this study was conducted with specific aims. This research only focuses on the hazardous waste generation trends at private healthcare sector of Dhaka city. The research objectives can be summarized in the form of following question:

1) How much hazardous waste is produced from private healthcare facilities on 'per patient per day' basis?

2) What are the epidemiological risks posed by this hazardous healthcare waste?

3) Which policies, frameworks and technologies are in place for the overall disposal and treatment of hazardous healthcare wastes?

\section{Defining Medical Waste}

There are different concepts of waste management. However, in this research the concepts proposed by WHO (2014) such as classification of medical waste, the nature of medical waste and hospital waste management techniques and methods are described.

WHO (2014) defines medical waste as waste produced by health care activities including a wide range of materials, from used syringes and needles to soiled dressings, diagnostic samples, body parts, pharmaceuticals, chemicals, blood, medical devices and 
radioactive materials. United States Environmental Protection Agency (EPA, 2017) defines medical waste as a subset of wastes generated at health care facilities, such as hospitals, physicians' offices, dental practices, blood banks and veterinary hospitals/clinics, as well as medical research facilities and laboratories. Generally, medical waste is healthcare waste that may be contaminated by blood, body fluids or other potentially infectious materials and is often referred to as regulated medical waste. Karamouz et al. (2007) described medical waste as hazardous and nonhazardous wastes for general classification.

WHO (2014) has classified medical wastes into eight different categories, which are as follows:

1) Pathological waste

2) Chemical waste

3) Sharps

4) Pharmaceutical waste

5) Pressurized containers

6) Radioactive waste

7) Infectious waste and potentially infectious waste

8) General waste

\section{Hospital Waste Management Systems in Different Developing Countries}

In developing countries, some processes e.g., on-site incineration, steam disinfection, microwave disinfection, autoclave disinfection and mechanical/chemical disinfection are currently in use for managing harmful waste but on a very small scale. Normally, incineration practices are found in Argentina, Brazil, Peru, Pakistan, India and Bangladesh. In developing countries, hospital waste incinerators operate under sub-optimal conditions and mostly incinerators are non-functional due to different reasons. For example, hospital's administration focus mostly on installing incinerators but they do not pay attention to its functioning and maintenance.

A study done by Subramani et al. (2014) showed that in India, on average $420461 \mathrm{~kg}$ of medical waste is generated every day. Only $240682 \mathrm{~kg}$ of that waste is treated while the rest half of the waste remains untreated. Asante et al. (2014) also reported that, in Ghana, 6851 beds are available for patients and each bed is generating $1.2 \mathrm{~kg}$ of medical waste per day. Moreover, around $83 \%$ of the selected health care facilities in Ghana did not segregate their medical waste. A study done by Joshi (2013) indicated that in Nepal, around $1.7 \mathrm{~kg} \mathrm{bed}^{-1} \mathrm{day}^{-1}$ waste was produced. Of which, $0.48 \mathrm{~kg} \mathrm{bed}^{-1}$ day $^{-1}$ generated waste was found to pose health risks (Table 3 ). This study also illustrated that in Nepal, mostly government and also private hospitals lacks the ability to systematically segregate the waste at the point of waste generation. Also, strict adherence to guidelines for color coding and labeling the waste containers aren't practiced by hospital employees as it is the case for Dhaka city (Rahman and Rahman. 2010). Generally, medical waste is collected in a big container, then it is mixed up with municipal waste, as a result the entire waste become hazardous and pollute the environment. Improper management of health care waste can badly affect the health of the hospital's staff, patients, waste workers and general public.

\section{Methodology}

For the purpose of establishing a methodology for healthcare waste generation study, instructions from WHO (2014) 'Safe management of wastes from healthscare activities' second edition were incorporated in this study. The instruction from pages 14 and 15 of WHO (2014) has been mentioned below as published.

"Variations in waste generation according to the type or level of health-care facility, or between rural and urban health-care facilities, may reflect differences in services provided, scale, organizational complexity, availability of resources and the number of medical and other staff. Regulations or policies on waste classification as well as segregation practices affect the breakdown of wastegeneration rates. Dissimilarities among low-, middle- and high income countries may be partly due to differences in resources, services provided, available wastemanagement systems and the proportion of single-use disposable items.

Average waste generation rates are calculated in kilograms (kg) per day or $\mathrm{kg}$ per year. Kilograms per occupied bed per day and $\mathrm{kg}$ per patient per day, are used especially when comparing different health-care facilities with different levels of activities. If inpatient occupancy rates and the daily number of outpatients are not available, the total number of beds is often used to estimate $\mathrm{kg}$ per bed per day. For analyzing departments within a health system, Tudor et al. (2005) suggests using kg per person per month (where "person" refers to both patients and staff) as a more accurate and stable measure of activity and as a tool to identify departments that could benefit from waste reduction, reuse and recycling.

Waste-generation data from other countries must be used with caution because of the wide variability even within a country and the many factors that influence the rates. They may be useful for order-of-magnitude estimations, but should not be used for detailed planning, budgeting or procurement. Even a limited survey will probably provide more reliable data on local waste generation than any estimate based on data from other countries or types of establishment."

This study is based on both primary and secondary sources. Secondary data (Monthly report of PRISM Bangaladesh's Medical waste Management Program. Amount of waste generated daily for each HCF in a month is tabulated in this report.) regarding hospital waste management techniques was collected from internet sources, books, journal articles, reports and PRISM Bangladesh Survey Report (2005). 
Table 1: Percentage of selected health care facilities categorically

\begin{tabular}{lllll}
\hline $\begin{array}{l}\text { Health Care Facility } \\
\text { (HCF) category }\end{array}$ & $\begin{array}{l}\text { No. of HCF's listed by } \\
\text { PRISM Bangladesh (2015) }\end{array}$ & $\begin{array}{l}\text { Percentage } \\
\text { of HCF's }\end{array}$ & $\begin{array}{l}\text { No. of selected HCF's for } \\
\text { secondary data collection }\end{array}$ & $\begin{array}{l}\text { Percentage } \\
\text { of HCF's }\end{array}$ \\
\hline Hospitals & 258 & $42.85 \%$ & 21 & $42 \%$ \\
Clinics & 148 & $24.58 \%$ & 13 & $26 \%$ \\
Diagnostic centers & 170 & $28.24 \%$ & 13 & $26 \%$ \\
Labs & 12 & $1.99 \%$ & 1 & $2 \%$ \\
Dental clinics & 14 & $2.32 \%$ & 2 & $4 \%$ \\
Total & 602 & $100 \%$ & 50 & $100 \%$ \\
\hline
\end{tabular}

Qualitative methods were used to collect primary data, including interviews with key informants using question guides composed of both open and close ended questions. Interviews were held with the hospital's staff, doctors, administration and general public living near the dumping sites. To view onsite conditions of the hospital waste and to collect visual data, field visits were made where personal experience was used and observations were made. For calculating the waste generation rate, secondary data obtained from PRISM Bangladesh has been used.

\section{Sample Size of the Study}

At present, PRISM Bangladesh, a renowned NGO based in Dhaka city, has been operating at a large scale to collect hospital waste from health care facilities and to subsequently processing and treatment of these hazardous waste. Under their medical waste management program, currently 602 private health care facilities are registered. From these $602 \mathrm{HCF}$ 's, $50 \mathrm{HCF}$ 's were randomly selected while maintaining the percentage of different types of HCF's. The overall categories of HCF's were 5. The duration of time for which the data was collected was April-May-June of 2015. Personal visits were made to hospitals and waste disposal site to record the actual conditions.

\section{Study Area}

This research was conducted in Dhaka city and was selected because of a number of health issues emerged during the last couple of decades. Due to overpopulation, the government hospitals are not able to provide the basic medical facilities to the patients too often. For this reason, to get urgent access to basic medical facilities, most people prefer to go to the private hospitals. Also, government medical facilities houses huge number of poor patients as floating patients since those poor patients can't afford a bed financially. The floating patients aren't often documented properly and their number vary widely. The undocumented floating patients can significantly increase the waste generation rates. As a result, the waste generation rates from private healthcare facilities and government facilities vary by significant margin. To understand this margin, separate studies are needed for the private and government healthcare sector. Due to the availability of detailed secondary data (obtained from PRISM Bangladesh) of waste generation from private HCF's the researchers opted for the private healthcare sector. Therefore, to describe, evaluate and compare between the existing practices of hospital waste management in government and private hospitals, Dhaka city was selected. To get the information about hospital waste management, interviews with hospital staff, management and medical students have been conducted. These interviews were conducted in 3 private health care facilities. Names of these hospitals are not mentioned due to confidential reasons.

\section{Site Selection}

In the city of Dhaka, there are approximately 900 private healthcare facilities. At present, 'PRISM Bangladesh' conducts medical waste management program within Dhaka city. 602 health-care facilities are currently participating in this program. We'hv collected secondary data of 50 HCF's from PRISM Bangladesh. The selections of HCF's were their categorical percentage of inclusion in the PRISM roster which has been illustrated in Table 1.

\section{Data Analysis}

In Bangladesh, the precise number of beds and diagnostic tests aren't disclosed by private HCF authorities without government order. Due to the lack of reliable data of bed numbers and tests done in HCF's the researchers has opted to find out medical waste generation rates in terms of both $\mathrm{kg} \mathrm{day}^{-1}$ and $\mathrm{kg} \mathrm{bed}^{-1}$ day $^{-1}$. The collected data from PRISM for the 50 selected HCFs has been summarized in Table 2.

The segregation criteria of medical wastes followed in different countries varies a lot according to the country's rules and regulations. While mathematical models for generation of hospital waste in Iran developed by Sabour et al. (2007) is more easy to implement, different approach is needed for the case of Bangladesh. For the purpose of estimation of hazardous waste generation from private HCF's of Dhaka city, the researchers found that the formula used by Patwari et al. (2009) is the most suitable. Equation (1) has been used to calculate the estimated total hazardous waste generated per day from private healthcare facilities. Equation (2) has been used to calculate the average hazardous waste generated in terms of per bed per day 
from the private healthcare facilities. The final steps of the calculation are below:

$$
\begin{aligned}
& \gamma=\tau_{c b} \omega_{c b}+\tau_{h b} \omega_{h b}+\tau_{d t} \omega_{d t} \\
& \bar{\omega}=\left(\omega_{c b}+\omega_{h b}+\omega_{d t}\right) / 3
\end{aligned}
$$

$\gamma=$ Total hazardous waste generated per day (for private healthcare facilities)

$\bar{\omega}=$ Avg. hazardous waste per bed per day (for private healthcare facilities)

$\tau_{h b}=$ Total no. of hospital beds in Dhaka city (13650)

$\omega_{h b}=$ Avg. hazardous waste per hospital bed per day in sampled hospitals $\left(0.15 \mathrm{Kg} \mathrm{bed}^{-1}\right.$ day $\left.^{-1}\right)$

$\tau_{c b}=$ Total no. of clinic beds in Dhaka city (6102)

$\omega_{c b}=$ Avg. hazardous waste per clinic bed per day in sampled clinics $\left(0.11 \mathrm{Kg} \mathrm{bed}^{-1}\right.$ day $\left.^{-1}\right)$

$\tau_{d t}=$ Total no. of diagnostic center test per day in Dhaka city (15100)

$\omega_{d t}=$ Avg. waste per diagnostic test in sampled diagnostic centers per day $\left(0.27 \mathrm{Kg} \mathrm{test}^{-1}\right.$ day $\left.^{-1}\right)$

$\gamma=(13650 * 0.15)+(6102 * 0.11)+(15100 * 0.27)=$ $6795.72 \mathrm{~kg} \mathrm{day}^{-1}$

Total solid waste generated in Dhaka city per day $=$ 5000 metric tons $=5000000 \mathrm{~kg}$.

So, hazardous health care waste generation percentage $=(6796 / 5000000) * 100=0.14 \%$.

Total health care waste generated in Dhaka city per day $=42$ metric tons $=42000 \mathrm{~kg}$.

Hazardous healthcare waste percentage of the total health care waste $=(6796 / 42000) * 100=16.18 \%$.

Avg. daily hazardous healthcare waste generation rate on per patient basis, $\bar{\omega}=(0.15+0.11+0.27) / 3=0.17$ $\mathrm{kg} \mathrm{bed}^{-1}$ day $^{-1}$.

\section{Results and Discussion}

According to Tudor et al. (2005), different parameters influence the amount generated and composition of medical waste. The parameters include the size of the HCF's in consideration, the type of treatment provided and the waste segregation method followed onsite. The size of the private healthcare facilities in Dhaka city varies depending on the type of treatment provided. This study shows that hazardous health care waste generation rates of private HCF's is $0.17 \mathrm{Kg} \mathrm{bed}^{-1}$ day $^{1}$. This is lower than other research results. Because in Bangladesh, economically solvent people often visit private HCF's for minor health issues which results in lower waste generation. As a result, private HCF's generate less medical waste. In case government HCF's, the number of floating patients aren't included in total bed number but the wastes produced from the treatment of these floating patients makes the waste generation rates comparatively higher. Also, our result for hazardous healthcare waste percentage of total health care waste $(16.18 \%)$ is within WHO specified range (10$25 \%$ ). It was observed that, during data collection period (April-May-June of 2015), for all categories of HCF's, hazardous medical waste generation gradually increased with time. In April, the lowest quantity of hazardous medical waste was recorded; subsequently it was highest in June. This indicated the seasonal variation; as summer intensified followed by the start of rainy season, many diseases spread rapidly as shown by Noor and Munna (2015) which are diarrhea, dengue fever, pneumonia, influenza, Tuberculosis (TB), malaria, cholera, chikungunya, meningitis, food-borne gastroenteritis, salmonellosis and campylobacteriosis. It was evident from the collected data; the hospitals generated the largest portion of the hazardous medical waste; while labs and dental clinics produced lesser quantity (Table $2)$. For the healthcare workers to use bins without disruption to their normal routine, color coded bins placed conveniently. In spite of that there may be systematic error in measuring the waste relating to the size of the HCF's. In the cases of relatively larger HCF's ther is an increased possibility that some waste may leave a department without being weighed. While in smaller HCF's there may be some transfer of wastes among departments prior to being weighed. These effects could have contributed slightly to the large differences in the amount of waste being produced per bed. To contextualize the medical waste generation rate of Bangladesh with perspective to modern and developing countries, Table 3 has been formulated below.

\begin{tabular}{|c|c|c|c|c|}
\hline \multirow[b]{2}{*}{ HCF category } & \multicolumn{3}{|l|}{ Month } & \multirow[b]{2}{*}{ Total $(\mathrm{kg})$} \\
\hline & April (kg) & May $(\mathrm{kg})$ & June $(\mathrm{kg})$ & \\
\hline Hospitals & 9678.37 & 11148.7 & 13588.20 & 34415.27 \\
\hline Clinics & 688.60 & 815.7 & 900.15 & 2404.45 \\
\hline Diagnostic Centers & 1446.75 & 1766.7 & 1903.20 & 5116.65 \\
\hline Labs & 29.60 & 25.0 & 34.90 & 89.50 \\
\hline Dental Clinics & 51.00 & 53.0 & 57.00 & 151.00 \\
\hline Total & 11894.32 & 13809.1 & 16483.45 & 42186.87 \\
\hline
\end{tabular}

Table 2: Hazardous medical waste generation data summery from selected HCF's 
Table 3: Comparison of health care waste generation rate of Bangladesh with other countries

\begin{tabular}{ll}
\hline Countries & Hazardous health-care waste generation $\mathrm{rate}^{\left(\mathrm{Kg} \mathrm{bed}^{-1} \text { day }^{-1}\right)}$ \\
\hline Bangladesh, Patwari et al. (2009) & 0.28 \\
Norway, Bdour et al. $(2007)$ & 0.68 \\
UK, Bdour et al. (2007) & 0.57 \\
Greece, Komilis et al. (2011) & 0.33 \\
Brazil, Silva et al. $(2005)$ & 0.57 \\
Taiwan, Cheng et al. (2010) & 0.19 \\
Nepal, Joshi (2013) & 0.48 \\
Turkey, Birpinar et al. (2008) & 0.63 \\
Iran, Taghipour and Mosaferi (2009) & 0.30 \\
\hline
\end{tabular}

\section{Medical Waste Treatment and Disposal Methods Followed in Dhaka City}

The collected information through interviews with the hospital staff and visual examination by the researcher demonstrated that in private health care facilities, Solid Waste Management (SWM) system comprises of separate waste storage area at dedicated places within hospital vicinity. Sanitation staff including sweepers and waste collectors clean the hospital's individual area, collect the hospital waste and dispose of this waste at identical garbage heaps. PRISM Bangladesh collects this waste in covered vans and transports the waste to their waste disposal and treatment site in Gazipur. In these private HCF's color coding scheme for the collection of plastic, paper, glass and other infectious waste was observed by the researcher.

For effective onsite segregation of medical waste, Kumar et al. (2010) suggested a color coding scheme which is given below:

Green: For organic waste

Red: $\quad$ For risk waste with sharps

Blue: For risk waste without sharps

Black: For non-risk/General waste

Yellow: For radioactive waste

WHO formulated a color coding chart (Table 4) for the developing countries in 1997. Later, DGHS (DGHSDirectorate General of Health Services under purview of Ministry of Health and Family Welfare of the Government of the Peoples Republic of Bangladesh.) implemented their own color coding chart (Table 5) througn 'Manual for Hospital Waste Management' in 2001. Presently, the color coding chart described in Table 5 is standardized throughout government directives in all types of health care facilities in Bangladesh.

In private health care facilities respondents told to the researcher that after collection of waste from each ward, for temporary storage they have separate container and trolley outside the hospital building, sweepers throw-off all of the hospital waste in "Blue color" container and "Yellow color PRISM trolley".
Table 4: WHO recommended color code for developing countries

\begin{tabular}{ll}
\hline Type of waste & Color code \\
\hline Highly infectious & Red \\
Infectious, pathological, anatomical & Yellow \\
Sharp & Yellow colored box \\
Chemicals, Pharmaceuticals & Brown \\
Radioactive & Silver \\
General waste & Black \\
\hline
\end{tabular}

General waste

Table 5: Color code followed in Bangladesh

Recommended color code in

Bangladesh type of waste

General or non-hazardous

Infectious, Pathological, Anatomical

Sharp

Radioactive

Recyclable waste

Liquid

Color code

Black

Yellow

Red

Silver color

Green Blue

Respondents mentioned that, every early morning PRISM Bangladesh vans collect all of these wastes from these containers from the private hospitals clinics and labs and then transport this waste to PRISM Bangldesh's waste disposal and treatment site located near Gazipur city. In the final treatment site, autoclaving, incinerating, chemical disinfection, deep burial for amputed body parts, deep burial for sharp wastes and shredding machine for recyclable materials are used. Figure 1 graphically describes the integrated waste collection and disposal system implemented by PRISM Bangladesh. Figure 1. Integrated waste collection and disposal system of PRISM Bangladesh.

Storage, Transportation and Final Disposal of Medical Waste

\section{Burning of Hospital Waste}

In private HCF's researcher also observed that behind the hospital buildings, big holes were found. When the sweepers were asked about the reality of these holes, they replied that, on the instructions of the hospital's administration, they filled these holes with infectious and hazardous waste which they got rid of by burning. When asked about the reason of burning this hazardous waste, respondent replied that hospitals lack onsite incineration plant. Therefore, for hospital waste management there is no other option than burning to get rid of this infectious and hazardous waste. 


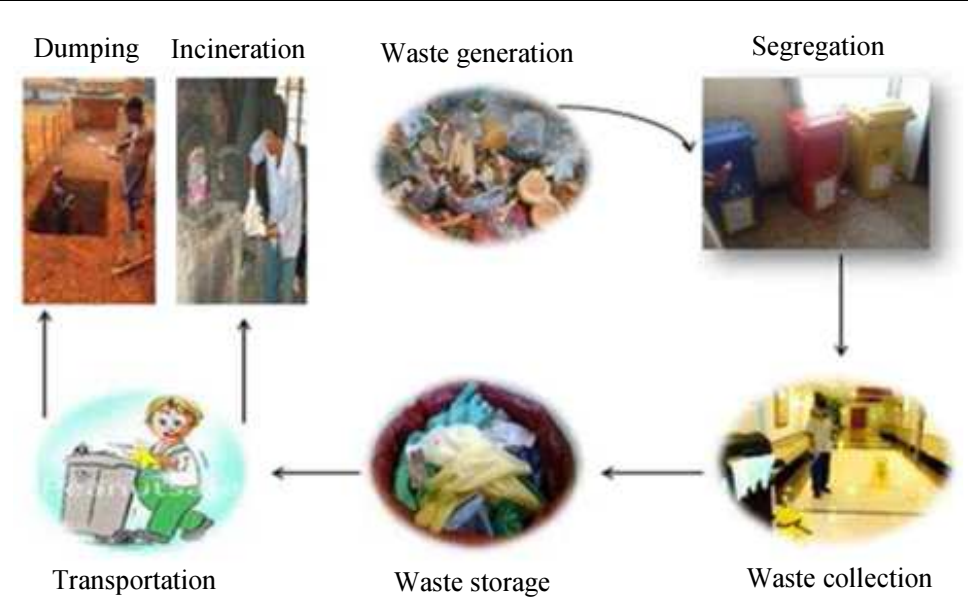

Fig. 1: Integrated waste collection and disposal system of PRISM Bangladesh

\section{Recycling of Waste}

Researcher came to know that empty glass/plastic bottles, containers and tins were sometimes re-used by doctor's assistants and compounders without sterilizing them. However, recyclable products such as glucose bags, urine bags, tins, used syringes, paper; cardboard, plastic bottles and infusion tubes were collected and sorted by the sweepers and scavengers within hospitals premises and outside the hospital boundaries respectively. Sweepers and scavengers perform these duties without realizing the serious health issues such as Hepatitis B, C, HIV/AIDS and many other allergic issues which can be caused by handling and due to contact with these infectious/toxic wastes. On asking about the reason for the collected and sorted recyclable waste, respondents mostly replied that these recyclable products can be easily sold on for good prices at scrap yards.

\section{Recommendations}

The researchers carried out several on-site investigations at waste dumping and processing centers. Based on the observations made by multiple personnel associated with health-care waste management in Dhaka, a few improvements are recommended:

At present, medical waste management program is conducted in a handful of cities Bangladesh. Other major cities need to be covered by this program. Participation on this aspect by NGOs (Non-Government Organizations. Usually they are non-profit voluntary organizations funded by foreign donations.) like PRISM Bangladesh should be encouraged by the government. Also, through training and guidance supported by DGHS and NGOs, the application of guidelines and procedures associated with effective enactment of the law through DoE (Department of Environment of the Government of the Peoples Republic of Bangladesh) needs to be promoted. Municipal authorities should be also involved the medical waste management programs aside from their regular municipal solid waste collection.

Training of personnel associated with health care waste collection, transportation and disposal should be arranged periodically to keep them up to date with newest frameworks and guidelines.

The government needs to formulate and establish an effective national framework, which can be applied in bigger cities as well as smaller cities.

It was observed that some medical staffs try to earn some extra money by selling used syringes and other disposed medical wastes. Drug addicts often buy these discarded medical wastes to administer drugs. Without proper treatment, the reuse of these medical wastes create epidemiological risks. The sales of discarded medical wastes should be prevented by the hospital authority and law enforcement agencies.

To increase mass awareness about the exposure risks of health care waste, public awareness campaigns should be arranged through both electronic and print media.

\section{Conclusion}

Many financially restrained counties like Bangladesh experience difficulties with management of healthcare wastes. Countries with huge populations and inadequate healthcare facilities may have floating patients in their government healthcare facilities. This can give skewed results while conducting healthcare waste generation surveys. To avoid this, independent surveys should be conducted for the government and private healthcare sectors. From this study, the following conclusions can be drawn:

Our result for hazardous health care waste percentage of total health care waste $(16.18 \%)$ is within WHO specified range (10-25\%). Average daily hazardous healthcare waste generation rate on per patient basis was found to be $0.17 \mathrm{~kg} \mathrm{bed}^{-1} \mathrm{day}^{-1}$ for the private healthcare sector. For a megacity like Dhaka, even low hazardous 
wastes generation rates can lead to the accumulation of large quantity wastes. This enormous amount of medical waste poses significant health risks to the people associated with waste disposal and treatment.

Absence of government guideline and application of environmental law aided by the people's ignorance and reluctance to the conservation of environment along with economical insolvency has acted as the major catalyst behind the failure of waste management system of Dhaka city. Awareness and education on medical waste issues should be raised among the general people. The government has the responsibilities of formulating appropriate policy that needs to be followed by all the HCF's Bangladesh.

In future, the researchers of this study aims to find out the health-care waste generation rates from government health-care sector and finally make a detailed comparison between the two health-care sectors.

\section{Acknowledgement}

We express our heartiest gratitude's to the Executive Director, Mazharul Islam (Deputy Program Coordinator) and Md. Istak Mahfuz (Environment Monitoring Officer) of PRISM Bangladesh Foundation for providing us with necessary information for this research.

\section{Author's Contributions}

Md. Yousuf Rumi: Field investigation, data collection, general writing, preparing manuscript and formatting of article.

Rezaul Karim: Preparation of framework and work schedule, data analysis, abstract writing and proofreading of manuscript.

\section{Ethics}

Both authors have read and approved the manuscript and there are no ethical issues involved.

\section{References}

Ahmed, R., 1997. Hospital waste management in Pakistan. Case Study Report, Special Waste Fraction: Hospital Waste. Urban Waste Expertise Programme.

Akter, N., 2000. Medical waste management: A review. Environmental Engineering Program: School of Environment, Resources and Development, Asian Institute of Technology, Khlongluang, Pathumthani 12120, Thailand.

Asante, O.B., E. Yanful and E.B. Yaokumah, 2014. Healthcare waste management; it's impact: A case study of greater Accra region, Ghana. Int. J. Sci. Technol. Res., 3: 106-112. DOI: 10.2139/ssrn.2410909
Bdour, A., B. Altrabsesh, N. Hadadin and M. Al-Shareif, 2007. Assessment of medical waste management practice: A case study of northern part of Jordan. Waste Manage., 27: 746-759.

DOI: 10.1016/j.wasman.2006.03.004

Birpinar, M.E., M.S. Bilgili and T. Erdogan, 2008. Medical waste management in Turkey: A case study of Istanbul. Waste Manage., 29: 445-448.

DOI: $10.1016 /$ j.wasman.2008.03.015

Cheng, Y.W., K.C. Li and F.C. Sung, 2010. Medical waste generation in selected healthcare facilities in Taiwan. Waste Manage., 30: 1690-1695.

DOI: 10.1016/j.wasman.2010.04.006

EPA, 2017. Medical waste. United States Environmental Protection Agency.

JICA, 2005. Clean Dhaka master plan, the study on solid waste management in Dhaka city. Final Report, Japan International Cooperation Agency.

Joshi, H.D., 2013. Health care waste management practice in Nepal. J. Nepal Health Res. Council, 11: 102-108. PMID: 23787539

Kabir, Z.N., C. Tisheman, A.H. Torres, A.M.R. Chowdhury and B. Winblad et al., 2003. General and rural-urban differences in reported health status by older people in Bangladesh. Archives Gerontol. Geriatr., 37: 77-91. DOI: 10.1016/s0167-4943(03)00019-0

Karamouz, M., B. Zahraie, R. Kerachian, N. Jaafarzadeh and N. Mahjouri, 2007. Developing a master plan for hospital solid waste management: A case study. Waste Manage., 27: 626-638.

DOI: 10.1016/j.wasman.2006.03.018

Komilis, D., N. Katsfaros and P. Vassilopoulos, 2011. Hazardous medical waste generation in Greece: Case studies from medical facilities in Attica and from a small insular hospital. Waste Manage. Res., 29: 807-814. DOI: 10.1177/0734242x10388684

Kumar, R., E.A. Khan, J. Ahmed, Z. Khan and M.M. Nousheen et al., 2010. Healthcare Waste Management (HCWM) in Pakistan: Current situation and training options. J. Ayub Med. Coll. Abottabad, 22: 101-106.

Muhlich, M., M. Scherrer and F.D. Daschner, 2003. Comparison of infectious waste management in European hospitals. J. Hospital Inf., 55: 260-268. DOI: $10.1016 /$ j.jhin.2003.08.017

Noor, R. and M.S. Munna, 2015. Emerging diseases in Bangladesh: Current microbiological research perspective. Tzu Chi Med. J., 27: 49-53. DOI: $10.1016 /$ j.tcmj.2015.01.003

Patwari, M.A., W.T. O'hare, G. Street, K.M. Elahi and S.S. Hossain et al., 2009. Quantative assessment of medical waste generation in the capital city of Bangladesh. Int. J. Integrated Waste Manage., Sci. Technol., 29: 2392-2397.

DOI: 10.1016/j.wasman.2009.03.021 
PRISM Bangladesh Survey Report, 2005. Survey report of hospital waste management in dhaka city.

Rahman, M.M. and M.M. Rahman, 2010. Database preparation for improved healthcare waste management in Dhaka city with GIS. J. Civil Eng. (IEB), 38: 203-210.

Rasheed, S., S. Iqbal, L.A. Baig and K. Mufti, 2005. Hospital waste management in the teaching hospitals of Karachi. J. Pak. Med. Assoc., 55: 192-195.

Rumi, M.Y., O.S. Chowdhury and M.R. Karim, 2017. Epidemiological issues of hazardous medical waste management from private healthcare facilities- case study from Dhaka city of Bangladesh. Proceedings of the 1st International Conference on Engineering Research and Practice, (ERP' 17), Dhaka, Bangladesh, Feb. 4-5, pp: 54-59.

Rumi, M.Y. and M. Muhebb, 2016. A study on hazardous waste generation from private health-care facilities in dhaka city. BSc thesies, Islamic University of Technology, Gazipur, Dhaka, Bangladesh.

Sabour, R.M., A. Mohamedifard and H. Kamalan, 2007. A mathematical model to predict the composition and generation of hospital wastes in Iran. Waste Manage., 27: 584-587.

DOI: 10.1016/j.wasman.2006.05.010
Shinee, E., E. Gombojav, A. Nishimura, N. Hamajima and K. Ito, 2008. Healthcare waste management in the capital city of Mongolia. Waste Manage., 28: 435-441. DOI: 10.1016/j.wasman.2006.12.022

Silva, C.E.D., A.E. Hoppe, M.M. Ravanello and N. Mello, 2005. Medical waste management in the south Brazil. Waste Manage., 25: 600-605. DOI: 10.1016/j.wasman.2004.03.002

Subramani, T., P. Anitha and S. Sekar, 2014. Health-care waste management system. Int. J. Eng. Res. Pract., 4: 255-258.

Taghipour, H. and M. Mosaferi, 2009. Characterization of medical waste from hospitals in Tabriz, Iran. Sci. Total Environ., 407: 1527-1535.

DOI: $10.1016 /$ j.scitotenv.2008.11.032

Tudor, T.L., C.L. Noonan and L.E.T. Jenkin, 2005. Healthcare waste management: A case study from the National Health Service in Cornwall, United Kingdom. Waste Manage., 25: 606-615. DOI: $10.1016 /$ j.wasman.2004.10.004

WHO, 1994. Managing medical waste in developing countries. Report of a Consultation on Medical Wastes Management in Developing Countries.

WHO, 2014. Safe Management of Wastes from HealthCare Activities. 2nd Edn., World Health Organization, Geneva, ISBN-10: 9241548568, pp: 308. 